\title{
A Comprehensive Critique on Wool Grease Extraction, Properties and Applications
}

\author{
Hosam El-Din Zakaria El-Sayed*, Salwa Mowafi, Amira Abou El-Kheir, \\ E. M. El-Khatib \\ Textile Industries Research Division, National Research Centre, Dokki, Cairo, \\ Egypt.
}

$\mathbf{T}$ HE UTILIZATION of raw wool wax (grease) extracted from scouring effluent of fleece of sheep has been recognized two millennia ago. About seven centuries B.C., wool grease wax was extracted by Greek labors. Nowadays, tremendous amounts of wool wax are discharged each year into the scouring effluent of wool fleece. Restore of wool grease from textile effluent is of prime importance targeting environment protection. This article outlines the current and the possible ways of extraction of wool wax from coarse wool fleece; taking into consideration the economic and ecologic aspects. The methods of purification of the extracted wool grease into lanolin are also briefed.

Recent techniques; namely microwave and ultrasonic-assisted extraction and purification of wool wax, were outlined and briefly compared to the conventional heating method used for extraction of wool wax.

Chemical and physical characteristics of the extracted lanolin, which play important role in its utilization, are outlined. The current and future utilization of wool wax in textile and non-textile application are reported.

Keywords: Wool, Lanoline, Extraction, Purification, Utilization, Microwave, Ultrasonic.

\section{Introduction}

Recovery of many organic substances discharged into the effluent of textile mills is of prime importance from the ecological and economical points of view. Among others, these include sericin from the degumming process of natural silk, wool grease discharged with the scouring effluent from of raw wool fleece, and dyes from any coloration process for textiles. Restoring these substances, and others, from textile mills' effluent decreases the oxygen demand, both chemical and biological. The recycled materials are utilized in many textile and non-textile applications.

Although it is relatively expensive, woolen goods can survive in the auctions due to their versatile properties, such as warmth, strength, and wrinkle resistance. During processing of wool from fleece to final products, many recyclable organic substances are discharged; wool grease is one of those materials.
Wool fabrics have been used since the bronze era in Europe and almost fourteen centuries B.C. in Egypt. Wool types are classified according to fibre diameter and length. The major sheep breeds and characteristics of the wool they produce are shown in Table 1. The most commonly used wool for manufacturing the finest wool is the "Merino", which was grown in the South Western part of Europe thousands of years ago. Export of Merino wool was prohibited until the mid of eighteenth century. The most notable of these is Australia, where it has been developed to produce highly prized wool with exceptional fineness, length, colour, lustre and crimp.

Here are some basic characteristics of coarse wool breeds that are commonly available among colored sheep in Australia and New Zealand.

*Corresponding author e-mail: hosam@trdegypt.org

DOI: 10.21608 /ejchem.2018.4214.1372

(C2017 National Information and Documentation Center (NIDOC) 
TABLE 1. Properties of wool from major sheep breeds [1].

\begin{tabular}{cccc}
\hline Breed & $\begin{array}{c}\text { Mean fibre diameter } \\
\text { range/( } \boldsymbol{m})\end{array}$ & Staple length & Fibre type \\
\hline range $/(\mathbf{m m})$ & $60-100$ & Fine \\
Merino & $17-25$ & $75-125$ & Medium \\
Romney & $28-33$ & $125-175$ & Long, lustrous \\
Coopworth & $33-37$ & $125-175$ & Coarse, long, lustrous \\
Perendale & $35-39$ & $100-150$ & Long, bulky \\
Polwarth & $31-35$ & $75-100$ & Medium, Fine \\
Lincoln & $23-26$ & $175-250$ & Long, lustrous \\
Leicester & $39-41$ & $150-200$ & Long, lustrous \\
Suffolk & $37-40$ & $75-100$ & Short, bulky \\
Hampshire & $30-34$ & $50-75$ & Short, bulky \\
Cheviot & $26-30$ & $75-100$ & Bulky, low lustre \\
Blackface & $28-33$ & $180-280$ & Coarse \\
\hline
\end{tabular}

\section{Composition of raw wool}

Wool is a renewable natural proteinic staple fibre produced from sheep fleece. The raw fiber is usually contaminants with three different components namely; natural, acquired and applied. These contaminants, produced by the sheep, consist of wool wax and suint. The latter comprises a mixture of primarily potassium-based salts of fatty acids, such as oleic and stearic acids. It was found that suint is secreted from sweat glands of the sheep and dries on the skin and wool fibre. Suint is very water-soluble and can be withdrawn from the native wool by extraction in aqueous medium $[2,3]$.

Acquired impurities are picked up from the sheep's surroundings and they are sorted into mineral or vegetable contaminants. The former comprise stones, dirt and sand which could be removed by washing. Vegetable matter found in wool fleece includes seedpods, grass straw, twigs, and pieces of plant tissue. Applied chemical impurities; Viz. fertilizers and dip were directly applied to the sheep or to their pasture. These generally only occur in trace quantities and can be very difficult to separate from the other contaminants [4].

Egypt.J.Chem. 61, No. 6 (2018)

\section{Wool Greases}

Fats and oils constitute the main components of wool wax [5], excreted from the sebaceous gland attached to the root of each wool fibre in the basal sheet of the sheep's skin and gathers inside the wool fibre while it grows [2, 6, 7]. This lubricant protects the wool from the effect of weathering such as sun, wind and rain. Wool grease constitutes about $10-25 \%$ of the sheared greasy wool [7].

Wool grease in its crude form is highly viscous and greasy dark paste. So, the crude wool grease must be refined before it can be used for different fields even for less critical uses [3]. The purified wool grease is usually known either as lanolin, wool wax or "wool fat".

\section{Physical properties of lanoline}

Lanolin is a pale-yellow, wax-like substance with pronounced emollient (or soothing) properties. It melts at $36{ }^{\circ} \mathrm{C}$ to $42{ }^{\circ} \mathrm{C}$. It is waterinsoluble, but it can mix without separation with two folds of its weight of water, sparingly soluble in alcohol, slightly soluble in hot alcohol, and freely soluble in ether and chloroform [8]. 
It blends and combines well with practically all other materials used in cosmetics and pharmaceuticals due to the strong emulsifying and penetrating properties of lanolin. Its adhesive property makes it an excellent candidate for use as a plasticizer in adhesives and resins. Apart from its use in cosmetic and pharmaceutical industries, lanolin derivatives are commonly utilized in many industrial sectors, such as plastics, lubricants, textile oil, concrete, paint, and ink $[3,7]$.

\section{Chemical Composition of Lanolin}

Lanolin consists of a complex mixture of esters and polyesters of high molecular weight alcohols and fatty acids [9]. Isolation of lanolin esters is extremely difficult and no conclusions were found that identify the individual esters which exist in lanolin. Detailed analyses have been carried out on fatty acids and alcohols that the esters were formed (Table 2) $[3,9,10]$.

Upon saponification, it was found that wool wax acids comprise alkanoic, $\alpha$-hydroxy and $\omega$-hydroxy acids. Each group has three distinct series which are normal, iso- and anteiso- as shown in Fig.1 [3, 11].

Wool wax alcohols are the materials which derived from the saponification of wool wax. The depth investigations of fresh wool wax sample with liquid gas chromatography and mass spectroscopy represented that wool wax doesn't contain glycerides which imparted waxy touch to it, the composition of the total alcohols of the wool wax is elucidated in Table $3[3,12]$.

TABLE 2. Constituents of lanoline fatty acids [3, 11].

\begin{tabular}{lcccc}
\hline \multicolumn{1}{c}{ Lanolin acid } & $\begin{array}{c}\text { Number } \\
\text { identified }\end{array}$ & Content (wt \%) & Carbon length & $\begin{array}{c}\text { Carbon length major } \\
\text { fractions }\end{array}$ \\
\hline Normal acids & 27 & 12.1 & $\mathrm{C} 8-\mathrm{C} 38$ & $\mathrm{C} 14, \mathrm{C} 16, \mathrm{C} 24, \mathrm{C} 26$ \\
Iso acids & 17 & 22.1 & $\mathrm{C} 8-\mathrm{C} 40$ & $\mathrm{C} 14, \mathrm{C} 16, \mathrm{C} 18, \mathrm{C} 20, \mathrm{C} 26$ \\
Anteiso acids & 18 & 26.3 & $\mathrm{C} 7-\mathrm{C} 41$ & $\mathrm{C} 15, \mathrm{C} 19, \mathrm{C} 21, \mathrm{C} 25, \mathrm{C} 27$ \\
Normal $\boldsymbol{\alpha}$-hydroxy acids & 23 & 21.8 & $\mathrm{C} 10-\mathrm{C} 32$ & $\mathrm{C} 16$ \\
Iso $\alpha$-hydroxy acids & 12 & 4.5 & $\mathrm{C} 12-\mathrm{C} 34$ & $\mathrm{C} 18-\mathrm{C} 24$ \\
Anteiso $\alpha$-hydroxy acids & 12 & 0.8 & $\mathrm{C} 11-\mathrm{C} 33$ & $\mathrm{C} 23-\mathrm{C} 25$ \\
Normal $\omega$-hydroxy acids & 14 & 3 & $\mathrm{C} 22-\mathrm{C} 36$ & $\mathrm{C} 30, \mathrm{C} 32$ \\
Iso $\omega$-hydroxy acids & 8 & 0.8 & $\mathrm{C} 22-\mathrm{C} 36$ & $\mathrm{C} 30, \mathrm{C} 32$ \\
Anteiso $\omega$-hydroxy acids & 7 & 1.3 & $\mathrm{C} 23-\mathrm{C} 35$ & $\mathrm{C} 25, \mathrm{C} 31$ \\
Total & 138 & & & $\mathrm{C} 16, \mathrm{C} 18$ \\
Unsaturated fatty acids & 42 & 2.1 & & \\
Poly hydroxy fatty acids & & 4.7 & & \\
Total fatty acids confirmed & 180 & 99.5 & & \\
\hline
\end{tabular}

TABLE 3. Composition of mono and 1.2 diols alcohols wool wax alcohol.

\begin{tabular}{lcccc}
\hline \multicolumn{1}{c}{ Lanolin Alcohols } & $\begin{array}{c}\text { Number } \\
\text { identified }\end{array}$ & Content (wt. \%) & Carbon length & $\begin{array}{c}\text { Carbon length major } \\
\text { fractions }\end{array}$ \\
\hline Normal- monoalcohol & 16 & 1.6 & $\mathrm{C} 14-\mathrm{C} 34$ & $\mathrm{C} 24, \mathrm{C} 26$ \\
Iso-monoalcohol & 11 & 6.5 & $\mathrm{C} 14-\mathrm{C} 34$ & $\mathrm{C} 20, \mathrm{C} 22, \mathrm{C} 26$ \\
Anteiso-monoalcohol & 11 & 9 & $\mathrm{C} 17-\mathrm{C} 35$ & $\mathrm{C} 21, \mathrm{C} 25, \mathrm{C} 27$ \\
Nomal-Aliphatic 1,2 diols & 14 & 0.4 & $\mathrm{C} 12-\mathrm{C} 25$ & $\mathrm{C} 16, \mathrm{C} 18, \mathrm{C} 20$ \\
iso-Aliphatic 1,2 diols & 9 & 5.9 & $\mathrm{C} 14-\mathrm{C} 30$ & $\mathrm{C} 18, \mathrm{C} 20, \mathrm{C} 22, \mathrm{C} 24$ \\
anteiso-Aliphatic 1,2 diols & 8 & 2.4 & $\mathrm{C} 15-\mathrm{C} 29$ & $\mathrm{C} 21, \mathrm{C} 23$ \\
Total aliphatic alcohols & 69 & 25.8 & & \\
\hline
\end{tabular}




$$
\begin{gathered}
\mathrm{H}_{3} \mathrm{C}-\left(\mathrm{CH}_{2}\right)_{14}-\mathrm{COOH} \\
\text { n-hexadecanoic acid } \\
\text { (palmitic acid) } \\
\mathrm{H}_{3} \mathrm{C}-\underset{\mathrm{CH}-\left(\mathrm{CH}_{2}\right)_{13}-\mathrm{COOH}}{\mathrm{CH}}
\end{gathered}
$$

iso-hexadecanoic acid (iso-palmitic acid)<smiles>CCCCCCC(C)C(=O)O</smiles>

\section{4-methylhexadecanoic acid (anteiso-palmitic acid)}<smiles>CCCCCCC(O)C(=O)O</smiles>

\section{2-hydroxyhexadecanoic acid $\alpha$ (-hydroxy-palmitic acid)}

Fig. 1. Structure of wool wax acids.

Bedside the aliphatic alcohol, wool wax contains triterpene and sterols. Triterpenes are the hydrocarbons and they constitute a significant portion of the lipid substances of all plants and animals. These substances are considered as precursors to steroids in both plants and animals [6].

Sterols, steroid alcohols, are organic molecules occur naturally in plants, animals, and fungi. Cholesterol and isocholesterol are the major components of sterols. Isocholestrol is a mixture of sterols and the abundant components of it are: dihydrolanosterol $\left(\mathrm{C}_{30} \mathrm{H}_{25} \mathrm{O}\right)$ and dihydroagnosterol $\left(\mathrm{C}_{30} \mathrm{H}_{50} \mathrm{O}\right)$. Table 4 clarified the sterols in wool wax $[13,14]$.
TABLE 4. Constituents of steroid alcohols in lanolin.

\begin{tabular}{cc}
\hline Sterols in lanolin & $\begin{array}{c}\text { Content (wt. } \\
\mathbf{\%})\end{array}$ \\
\hline Cholesterol & 38 \\
dihydrocholesterol & trace \\
Cholesta-3,5-diene-7-one & 3.6 \\
Lanosterol & 14.8 \\
Dihydrolanosterol & 10.3 \\
3-hydroxylansta-8-en-7-one & 1.6 \\
Hydrocarbons and undetermined \\
alcohols
\end{tabular}

It has been reported from gas chromatographic investigations that the aliphatic alcoholic compounds in lanoline comprise $17.1 \%$ aliphatic nonalcohols, $8.7 \%$ aliphatic alkane-diols, 68.3 $\%$ sterol and triterpene alcohols, and $5.9 \%$ unidentified and polyols. Figure 2 shows the structural formula of sterols and lanosterols in wool wax alcohol [12].

\section{Extraction of wool grease \\ Methods of extraction}

The most usual method that applied to remove the grease and the dirty materials from wool consumes huge quantities of water and surfactants. The grease has been extracted from the scouring solids by Soxhlet extraction using dichloromethane as the solvent [15]. Because of the potential environmental effects of using this solvent and to diminish the time of the sample preparation, some new procedures have been developed to replace the traditional wool wax extraction procedure mainly microwave and supercritical fluids $[16,17]$.

Due to supercritical carbon dioxide is inert, non-toxic and non-polar solvent, it is considered as an appropriate candidate for extraction of wool grease [18].

It has been reported that, methanol or acetone as co-solvents change the polarity of $\mathrm{CO}_{2}$ and hence increasing the solubility of the components to extract. Supercritical fluid extraction using carbon dioxide and toluene as co-solvent has also been applied as effective for the extraction of the wool wax comparing with the conventional soxhlet system. Moreover, the time for the extraction is reduced considerably from $4 \mathrm{~h}$ with 
soxhlet to $45 \mathrm{~min}$ besides reducing the amount of the used solvent [19].

Microwave is considered as an interesting alternative technique for improving the extraction and overcomes organic contaminant extraction represents [20].

It was found that microwave extraction gives the same efficiencies as that achieved by classical

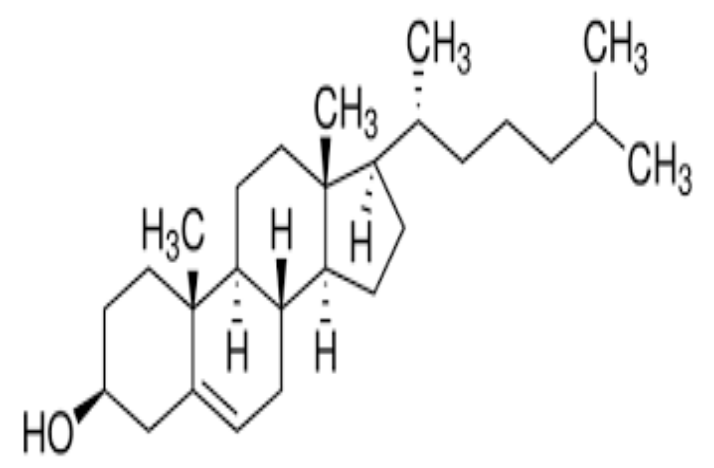

Cholesterol $\mathrm{C}_{27} \mathrm{H}_{46} \mathrm{O}$

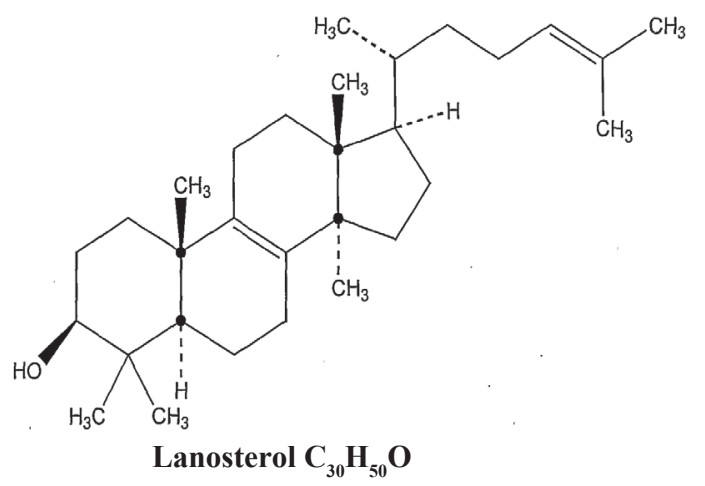

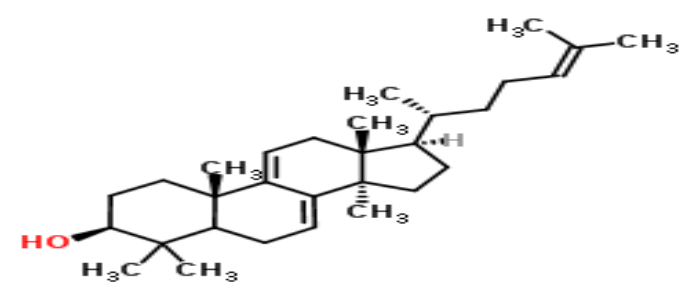

Agnosterol $\mathrm{C}_{30} \mathrm{H}_{48} \mathrm{O}$ soxhlet system with reducing the required time from $4 \mathrm{~h}$ to $8 \mathrm{~min}$ comparing to the soxhlet extraction technique where the amount of the applied solvent is reduced from 125 to $10 \mathrm{ml}$ [21]. Ultra-sonication is also considered as an ecofriendly effective degreasing system using distilled water and trichlorethylene as a medium of propagation-degreasing [22].<smiles>CC(C)CCCC(C)C1CCC2C3CCC4CC(O)CCC4(C)C3CCC12C</smiles>

Dihydrocholesterol $\mathrm{C}_{27} \mathrm{H}_{48} \mathrm{O}$

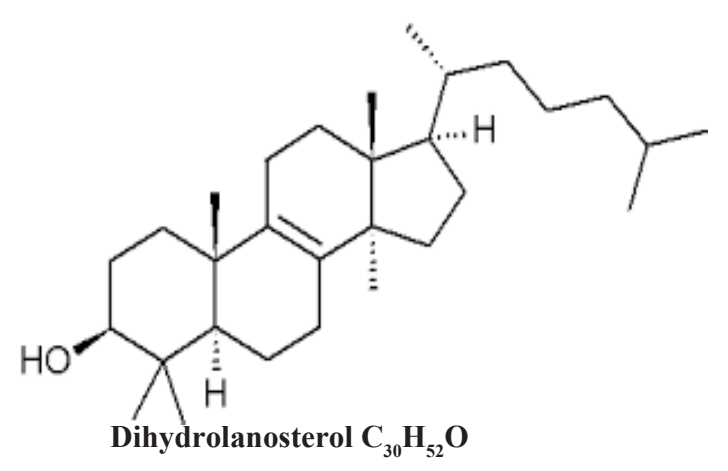

且

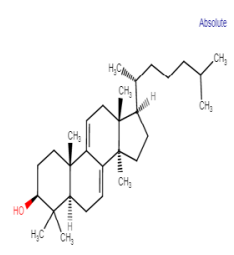

Dihydroagnosterol $\mathrm{C}_{30} \mathrm{H}_{50} \mathrm{O}$

Fig. 2. The structural formula of sterols and lanosterols in wool wax alcohol. 


\section{Wool Grease Recovery}

Owing to its low specific gravity, centrifuge is usually applied to recover the unoxidised wool wax from the scour effluent. At present, stacked disc centrifuges in a similar way to those used in dairy industry in either a 2 or 3 stage separation and purification process. The main processes used worldwide for wool grease recovery include some combination of thermal cracking and centrifuging.

\section{Single -Stage Wool Grease Recovery}

Scour effluent heated to at least $64^{\circ} \mathrm{C}$ is fed from above into the centre section of the primary centrifuge. Inside the centrifuge the effluent flows into the stack of cone shaped discs, which rotate at approximately $6000 \mathrm{rpm}$. In the disc stack the light wool grease outflows between the discs towards the core of the bowl and settled as primary cream. The second emulsion phase moves downwards between the discs owing to its higher density, from where it flows up the outer walls of the bowl and further discharged at the top of the centrifuge. Finally, any dirt and heavy solids are also carried down between the discs due to their higher density than the aqueous emulsion phase and then continuously separated through jets in the bottom of the bowl wall. The first cream is then put inside a thermal-cracking tank and left at approximately $90^{\circ} \mathrm{C}$ for more than five hours. At the end of this period the cream splits into three separate phases [23].

\section{Two-Stage Wool Grease Recovery}

In this system, the main centrifuges and thermal cracking tanks are still used but the cream and emulsion from the cracking tank in this time is put inside another tank of secondary centrifuges for further purification. The cream that obtained from the primary centrifuges is about $60-80 \%$ wool wax while that from the secondary centrifuges is characteristically extra of $99 \%$ pure [23].

\section{Three-Stage Wool Grease Recovery}

In this system a greater amount of the wool grease is extracted from the effluent by primary centrifuge. However, the produced primary cream is about $10-20 \%$ grease. Subsequently, this high volume low strength primary cream is then thermally cracked and passed through the secondary centrifuge at around $90^{\circ} \mathrm{C}$ resulting in a secondary cream having $70-80 \%$ wool grease. Still at $90^{\circ} \mathrm{C}$, the cream from the secondary centrifuge is then passed to a purifying centrifuge where it is mixed with clean hot water and is then separated to give lanoline with purity of about $99 \%$ [23].

\section{Purification of wool grease}

Purified wool grease is known as lanolin, which is the product that obtained from deodorization, decolonization, neutralization and elimination of water. Wool wax obtained from scouring is contaminated with detergent and suint and is, consequently named lanoline, as different from wool wax [24].

\section{First Stage of Refinement}

Due to the colour, odd odor and large amount of impurities, wool wax has to be refined further before its application [25].

The techniques and materials used for refining lanolin differ from one processor to another. Generally, the initial step includes the break of soaps and removal of acid-soluble impurities by refluxing the crude wool wax in an aqueous acid solution. After separation and elimination of the aqueous phase, alkaline treatment with caustic soda or soda ash was adopted to neutralize the free fatty acids in wool wax. The obtained soaps can be removed using mixtures of ethanol or isopropanol with water. This is to assure that the undesired impurities are washed from the wax mixture efficiently [23].

\section{Improving the Purity}

An additional decreasing of contaminants can be attained through treatment with adsorbents, such as activated carbon, followed by filtration. Residual odors and pesticides can be removed by exposure to high vacuum and simultaneous heating of the wool wax. This stage also decreases the amount of free lanolin alcohols [23].

\section{Colour Change}

At this step of the refinement process, most of the impurities - free fatty acids, detergents and pesticides, will be adequately reduced and the product will be pleasantly deodorized. By bleaching wax with common oxidative reagent such as: hydrogen peroxide, the dark colour will have vanished into a pale yellow. Small concentrations of another approved antioxidant, namely butylated hydroxytoluene (BHT), are usually added at the end of the refinement process. This objects the air getting to the lanolin and stopping superficial degradation by autoxidation [23]. 


\section{Final Step}

Finally, residual water is removed through a vacuum-drying process to give refined lanolin anhydrous with a scarcely recognizable odor.

\section{Applications of lanoline}

Lanolin is usually utilized in non-textile applications more than textile ones. The main fields in which lanoline are used are shown below:

\section{Anti-corrosive effect on ferrous metals}

Being non-toxic biodegradable substance, lanoline meets most of environmental legislations worldwide. Lanolin is also companionable with various additives that modify the uniformity and physiognomies of the resulting protective films (e.g. hard, soft, water soluble or insoluble). Consequently, lanoline liquors are commonly used in protection of metallic constructions which exist in a highly corrosive media. For instance, lanoline is used to protect marine water tanks and petroleum plants in salty water. The high diffusion potential of lanolin-based anti-corrosive liquors makes them the proper choice for rust treatment and prevention on automobile parts.

\section{Lubrication}

Lanolin imparts an appreciable lubricating and conservative effects to most of metals. It is used as lubrication grease for engineering parts, metal cutting oil, and lubricant for metal processing, e.g. rolling, grinding, and pressing.

\section{Textile and leather}

Tanning is an important step in leather processing to avoid its degradation. Lanolin is a usual additive where fats are added to impart softness to leathers after tanning. Additionally, lanolin is utilized in treatment of weathered leather, emollient shoe polishes and nourishing oil, gloss enhancer and emulsifier.

Lanoline is not widely used for textile applications. The only reported application of lanoline in the textile sector is as an emollient that gives a soft finish [23]. Doyle et al patented a process in which lanolin is used as a finishing agent for hosiery of nylon 6 . The general goal of this invention is to provide a finish which allows the production of nylon hosiery having a markedly improved handle or feel and approximately much more closely to the handle or feel of natural silk than has heretofore been possible [26].

The Proteinic and Man-made Fibres Department at the National Research Centre of
Egypt is currently engaged with a research project to propose new applications of lanolin in textile applications. Lanoline is a suitable hydrophobic candidate for many textile applications including coloration and finishing of natural and synthetic fibres.

\section{Personal care products}

Being a natural substance designed to soften skin and wool of sheep, the most important market for lanolin is the personal care products. Lanolin is an important ingredient in some of the most popular cosmetics and pharmaceuticals all over the world.

Lanolin is used in formulation of foundation creams, oil-based skin lotion, toilet soaps, after shave, shampoo, and hair bleaching agent [25].

\section{Other applications}

Lanolin is used by many manufacturers in producing varnishes, polishes, conditioners, hand creams, glues, belt wax, jointing paste, and concrete waterproofing products.

In the medical field, lanolin is used in burn dressing and wound sprays, ointment bases, support for wound healing, trans-dermal agent, dispersing agent for pigmenting medication, and ingredient in surgical adhesive tapes [23].

\section{Future Outlook}

By virtue of its viscous and sticky nature, and due to presence of active functional groups in lanoline; Viz. hydroxyl and carboxylic groups, lanoline may be an appropriate candidate for various applications in wet processing of textiles.

One of promising applications of lanoline in textiles is to impart water-repellency to textile fabrics for using in aquatic media and rains. Viscose fabric, for instance, is currently treated with lanoline to render it water-proof. Group of researchers at the National Research Centre in Egypt undertakes a simple technique for the production of mechanically durable super hydrophobic layer on viscose fibers via spraycoating of a lanolin-silicon rubber solution in petroleum ether.

On the other hand, recycled fabrics from junk textile wastes can be treated with lanoline to improve its smoothness and hence improve its appearance and performance attributes. In another recent trial, lanoline is currently tried as a thickening agent pigment printing polyester/ cotton blend. 


\section{Conclusion}

No accurate data or systematic studies are available for the percentage of wool grease which can be extracted from Egyptian wool; namely Ossemi, Barki, and Rahmani. This means that about $10-15 \%$ of the annual production of wool in Egypt is not properly utilized and discharged to drainage water causing loss of expected profits if properly extracted and exploited.

An intensive research work must be directed to complete characterization of wool wax extracted from Egyptian wool fleece to assign its probable industrial applications. Proper utilization of lanolin necessitates further work to find new applications for lanolin in textile sector. This will have positive ecological as well as economic impacts.

We believe that microwave irradiation and ultrasonic waves would be appropriate technologies to save time, energy, and chemicals during wool scouring. The process would be more convenient in case of coarse wools; an issue which needs future research studies.

\section{Acknowledgment}

This article is a part of a research project funded by the National Research Centre; project ID: 11070204 .

\section{References}

1. Teasdale D. C., Wool Testing and Marketing Handbook., Australia: University of New South Wales (1988).

2. López-Mesas M., Carrillo F., Gutiérrez M. C and Crespi M., Alternative methods for the wool wax extraction from wool scouring wastes, Grasa $Y$ Aceites, 58 (4), 402-407 (2007).

3. Sengupta A. and Behera J., Comprehensive view on chemistry, manufacturing \& applications of lanolin extracted from wool pretreatment, American Journal of Engineering Research, 3 (7), 33-43 (2014).

4. Madara D. S., Namango S. S., Wool grease recovery from scouring effluent at textile mill, Journal of Agriculture, Pure and Applied Science and Technology, 10, 1-9 (2014).

5. Lisovac A.M. and Shooter D., Volatiles from sheep wool and the modification of wool odour, Small Ruminant Research, 49, 115-124 (2003).
6. Seigler D.S., Plant Secondary Metabolism, Springer Science \& Business Media, LLC, Kluwer Academic Publisher, 1st edition (1998).

7. Schlossman M. L and McCarthy J. P., Lanolin and its derivatives, Journal of American Oils Chemists Society, 55 (4), 447-450 (1978).

8. Patel S., Nelson D. R., and Gibbs A. G., Chemical and physical analyses of wax ester properties, Journal of Insect Science, 1 (4), 1-7 (2001).

9. Moldovan Z., Jover E., and Maria Bayona J., Systematic characterisation of long-chain aliphatic esters of wool wax by gas chromatographyelectron impact ionisation mass spectrometry, Journal of Chromatography A, 952, 193-204 (2002).

10. Yao L and Hammond E. G., Isolation and Melting Properties of Branched-Chain Esters from Lanolin, The Journal of the American Oil Chemists' Society, 83 (6), 547-552 (2006).

11. Motiuk K., Wool Wax Acids A Review, Amerchol Corporation, A Unit of CPC International Inc., Amerchol Park, Edison, New Jersey, 08817, 56, 91-97 (1979).

12. Motiuk K., Wool Wax Alcohols: A Review, A Unit of CPC International, Inc., Amerchol Park, Edison, New Jersey 08817, 56, 651-658 (1978).

13. Ačimovič J and Rozman D., Steroidal Triterpenes of Cholesterol Synthesis, Molecules, 18, 40024017 (2013).

14. Crabtree H. E. and Truter E. V., Constitution of Some Steroid Esters of Wool Wax, Journal of the Science of Food and Agriculture, 25, 1441-1449 (1974).

15. Stewart R.G., Wool Scouring and Allied Technology, Christchurch, Wool Research Organisation of New Zealand (1988).

16. L'opez-Mesas M., Carrillo F and Crespi M., Microwave enhanced extraction of wool wax from solid wool scour wastes, Analytica Chimica Acta, 494, 255 (2003).

17. Alzaga R., Pascual E., Erra P and Bayona J.M., Development of a novel supercritical fluid extraction procedure for lanolin extraction from raw wool, Analytica Chimica Acta, 381 (1), 39 (1999).

18. Jones F.W., Bateup B.O., Dixon D.R and Gray S.R., Solubility of wool wax in supercritical 
carbon dioxide, The Journal of Supercritical Fluids, 10, 105 (1997).

19. L'opez-Mesas M., Christoe J., Carrillo F and Crespi M., Supercritical fluid extraction with cosolvents, The Journal of Supercritical Fluids, 35, 235 (2005).

20. Stout S. J., da Cunha A. R., and Allardice D. G.; Microwave assisted extraction coupled with gas chromatography electron capture negative chemical ionization mass spectrometry for the simpliced determination of imidazolinone herbicides in soil at the ppb level, Analytical Chemistry, 68, 653-658 (1996).

21. López-Mesas M., Carrillo F and Crespi M, Microwave enhanced extraction of wool wax from solid wool scour wastes, Analytica Chimica Acta, 494, 255 (2003).

22. Mîndru Tudorel B., Ovidiu P., Melinda P., Mîndru Iulia B and Augustin M., Study on Morphological and Structural Changes Induced by Ultrasonic Degrasing of Wool and Human Hair Wastes,
Annals of the University of Oradea Fascicle of Textile, Leather Work, Art. No. 36, page 7-12.

23. Sengupta A and Behera J., Comprehensive view on chemistry, manufacturing \& applications of lanolin extracted from wool pretreatment, American Journal of Engineering Research, 3 (7), 33-43 (2014).

24. Roy Chowdhury A. K., Textile Preparation and Dyeing, Oxford \& IBH publishing Co. Pvt. Ltd. (2006).

25. Rogers G. F and Mayhew Y. R., Thermodynamic and Transport Properties of Fluids, Oxford, Blackwell (1995).

26. Doyle W. F., Pacoag R. I., and Copenhaver D. L., Process of applying lanolin finish to nylon hosiery and heat setting the hosiery and products produced therefrom, US Patent 2,832,518 (1953).

(Received 25/6/2018; accepted 6/8/2018)

\section{نظرة نقدية على إستخلاص وخواص وتطبيقات شحم الصوف \\ حسام السيد، سلوى موافي، أميرة أبوالخير، إيمان الخطيب

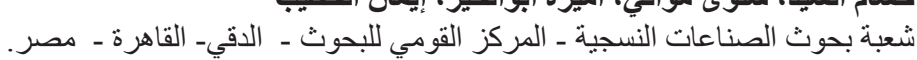

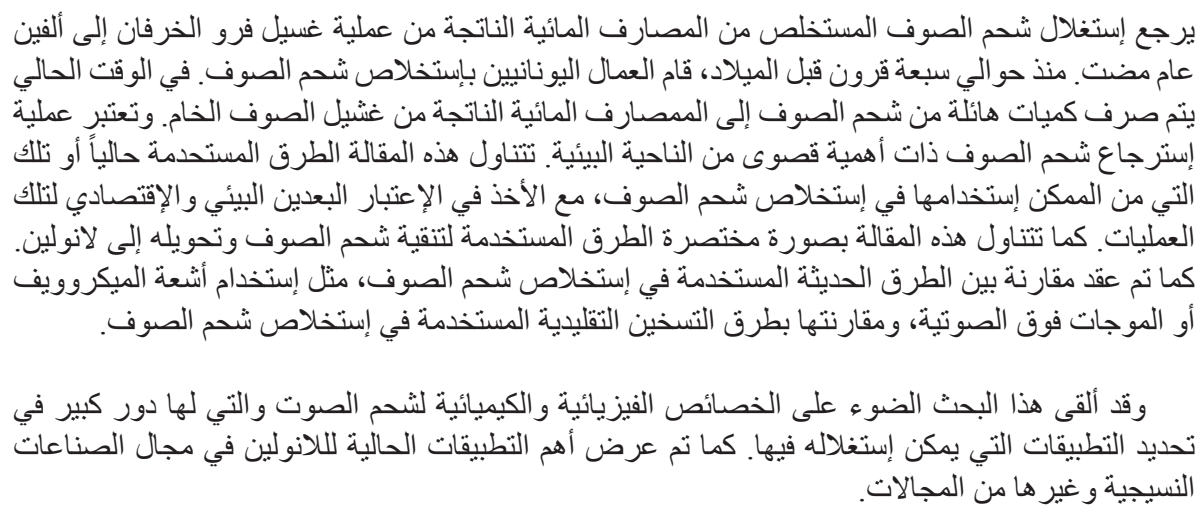

Egypt.J.Chem. 61, No. 6 (2018) 